\title{
Presence of Virulence Genes in Enterococcus Species Isolated from Meat Turkeys in Germany Does Not Correlate with Chicken Embryo Lethality
}

\author{
Julia Maasjost, ${ }^{1}$ Dörte Lüschow, ${ }^{1}$ Anne Kleine, ${ }^{1}$ Hafez M. Hafez, ${ }^{1}$ \\ and Kristin Mühldorfer $\mathbb{D}^{1,2}$ \\ ${ }^{1}$ Institute of Poultry Diseases, Freie Universität Berlin, 14163 Berlin, Germany \\ ${ }^{2}$ Leibniz Institute for Zoo and Wildlife Research, 10315 Berlin, Germany \\ Correspondence should be addressed to Kristin Mühldorfer; muehldorfer@izw-berlin.de
}

Received 25 April 2019; Revised 29 August 2019; Accepted 6 September 2019; Published 30 October 2019

Guest Editor: Moreno Bondi

Copyright (C) 2019 Julia Maasjost et al. This is an open access article distributed under the Creative Commons Attribution License, which permits unrestricted use, distribution, and reproduction in any medium, provided the original work is properly cited.

\begin{abstract}
Virulence-associated traits have frequently been studied in enterococci and are considered to contribute towards the pathogenicity of infections. In the present study, Enterococcus isolates were collected during diagnostic investigations from meat turkeys in Germany. Twenty-eight isolates of three different Enterococcus species were analyzed for five selected putative virulence traits to understand their potential role in the pathogenicity using the chicken embryo lethality assay. Ten E. faecalis, ten E. faecium, and eight E. gallinarum isolates were examined for the presence of common virulence genes and their phenotypic expression, namely, the cytolysin operon, five individual $c y l$ genes $\left(c y l L_{L}, c y l L_{S}, c y l M, c y l B\right.$, and $\left.c y l A\right)$, gelatinase (gelE), hyaluronidase ( hyl $\left.l_{E f m}\right)$, aggregation substance (asa1), and enterococcal surface protein (esp). The Enterococcus isolates showed significant species-dependent differences in the presence of genotypic traits $(p<0.001$ by Fisher's exact test; Cramer's $V=0.68)$. At least one gene and up to three virulence traits were found in E. faecalis, while six E. faecium isolates and one E. gallinarum isolate did not display any virulence-associated pheno- or genotype. More than half of the Enterococcus isolates $(n=15)$ harbored the gelE gene, but only $E$. faecalis $(n=10)$ expressed the gelatinase activity in vitro. The $h y l_{E f m}$ gene was found in five E. gallinarum isolates only, while seven isolates showed the hyaluronidase activity in the phenotypic assay. In Cramer's $V$ statistic, a moderate association was indicated for species $(V \leq 0.35)$ or genotype $(V<0.43)$ and the results from the embryo lethality assay, but the differences were not significant. All E. gallinarum isolates were less virulent with mortality rates ranging between 0 and $30 \%$. Two E. faecalis isolates were highly virulent, harboring the whole cyl-operon as well as gelE and asal genes. Likewise, one E. faecium isolate caused high embryo mortality but did not harbor any of the investigated virulence genes. For the first time, Enterococcus isolates of three different species collected from diseased turkeys were investigated for their virulence properties in comparison. The results differed markedly between the Enterococcus species, with $E$. faecalis harboring the majority of investigated genes and virulence traits. However, the genotype did not entirely correlate with the phenotype or the isolates' virulence potential and pathogenicity for chicken embryos.
\end{abstract}

\section{Introduction}

Enterococci are opportunistic bacterial pathogens that belong to the gastrointestinal flora of mammals and birds. Enterococcus faecalis and E. cecorum are responsible for the majority of enterococcal infections in poultry. E. faecalis is known to provoke amyloid arthropathy in layers [1] and the pulmonary hypertension syndrome in broilers [2]. This species is also a common bacterial cause of increased firstweek mortality in chicks [3] and can cause hepatic granulomas in turkey poults [4]. Clinical infections with E. cecorum became more prevalent over the past years and are responsible for severe inflammatory lesions of bones, joints, and internal organs in various poultry species including turkeys [5]. Besides animals, enterococci are a common cause of nosocomial infections in humans, and 
therapeutic options are impaired by multiresistant strains $[6,7]$. The role of livestock in contributing to antimicrobial and multidrug resistance by antibiotic treatment of large numbers of animals raise public health concerns and lead to a particular interest in virulence characteristics of circulating Enterococcus strains.

Resistance genes as well as virulence-associated genes are located on plasmids or transposons and can be transferred between different Enterococcus species and to other bacteria [8]. Several putative virulence traits have been described in enterococci. Cytolysin is a bacterial toxin with hemolytic activity, encoded by the cytolysin operon consisting of eight genes $\left(c y l R 1, c y l R 2, c y l L_{L}, c y l L_{S}, c y l M, c y l B, c y l A\right.$, and $\left.c y l I\right)$ [9]. Gelatinase, encoded by the chromosomal gelE gene, is an extracellular zinc endoprotease that enables enterococci to hydrolyze gelatin, collagen, and other small peptides [10]. Enterococcal colonization of host tissues is also facilitated by degradation of hyaluronic acids [11], encoded by the hyaluronidase gene $h y l_{\mathrm{Efm}}[12]$, as well as by different adhesins. Aggregation substance, encoded by asa1 [13], is a group of surface proteins that promotes bacterial adherence to renal tubular cells [14] and internalization by intestinal cells [15], while the enterococcal surface protein, encoded by esp, is associated with bacterial biofilm formation [16].

Animal infection experiments showed that some of these virulence traits may increase the pathogenicity of Enterococcus strains. In a rabbit model of $E$. faecalis endocarditis, mortality increased significantly in animals infected with bacterial strains that exhibited aggregation substance and cytolysin [17]. Another study indicated that strains with gelatinase activity seem to be more virulent in mice suffering from peritonitis than gelatinase-defective strains [18]. In humans, however, a study showed no association in enterococcal bacteremia cases between 14-day mortality and the presence of gelatinase, hemolysin, and the esp gene [19].

The presence of putative virulence genes and their expression in vitro do not allow definite conclusions about the virulence potential of bacterial strains under natural conditions $[20,21]$. An alternative way to determine the virulence of a microorganism is the embryo lethality assay, which allows correlations with genotypic and phenotypic characteristics. Wooley et al. [22] used this laboratory-based assay as an alternative to chicken challenge models for differentiation of virulent and avirulent $E$. coli strains. A subsequent study of Gibbs et al. [23] aimed to determine whether different virulence traits of E. coli, isolated from healthy broilers and from broilers with colibacillosis, were suitable for the prediction of chicken embryo lethality results. Some traits correlated significantly with high embryo lethality; however, this correlation was not $100 \%$ based on a single trait. Sturzenhecker [24] used the embryo lethality assay to compare the presence of virulence traits with embryo test results of Campylobacter jejuni and C. coli isolates from poultry. She found no virulence-associated correlation for toxin- or flagella-producing isolates, whereas low-molecular-weight outer membrane proteins seemed to be characteristic for highly virulent isolates. Two recent studies by Borst et al. [25] and Jung et al. [26] investigated pathogenic and commensal E. cecorum isolates to compare the results from the chicken embryo lethality assay. The authors found significantly higher mortality in embryos infected with pathogenic isolates from poultry species and production systems where E. cecorum infections cause serious disease outbreaks.

The aim of the present investigation was to characterize 28 isolates of three different Enterococcus species collected from diseased turkeys in Germany based on their virulence properties and correlations between their genotype, phenotype, and embryo lethality.

\section{Materials and Methods}

The present study belonged to a doctoral project (Dr. med. vet.) that aimed to investigate the prevalence, antimicrobial resistance, and virulence of enterococci isolated in 2010 and 2011 from commercial poultry flocks in North RhineWestphalia and Lower Saxony, Germany [27, 28]. In the present investigation, twenty-eight isolates from meat turkeys belonging to three different Enterococcus species, namely, ten E. faecalis, ten E. faecium, and eight E. gallinarum isolates, were selected for phenotypic and genotypic characterization and determination of the embryo lethality index. The isolates were cultured during disease diagnostics from turkey poults with yolk sacculitis as well as from internal organs of subadult birds (Table 1) and were kindly provided by Poultry Clinics and Laboratory Dr. Pöppel (Delbrück, Germany). The initial bacterial identification was based on the multiplex PCR protocol from the study of Jackson et al. [29] with specific primers targeting the $\operatorname{sod} A$ gene [30] to differentiate between E. faecalis, E. faecium, and other Enterococcus species. Subsequently, a 16S rRNA gene analysis [31] was used for confirmation and to identify all isolates at the species level.

2.1. Detection of Virulence Genes. The following enterococcal virulence genes were investigated, namely, five cytolysin genes $\left(c y l L_{L}, c y l L_{S}, c y l M, c y l B\right.$, and $\left.c y l A\right)$, gelatinase (gelE), hyaluronidase $\left(h y l_{E f m}\right)$, aggregation substance (asa1), and enterococcal surface protein (esp). All target genes, primer sequences, and the corresponding references are listed in detail in Tables S1 and S2 in Supplementary Materials. Bacterial DNA extraction and multiplex PCR analyses were performed according to the protocols from the study of Vankerckhoven et al. [32]. Two additional PCR assays were conducted for separate detection of the $c y l L_{S}$ gene and the cyl-operon according to Camargo et al. [33] and Gaspar et al. [34], respectively. Enterococcus faecalis MMH594 (kindly provided by M. Gilmore, Enterococcus II initiative, Broad Institute (broadinstitute.org)) was used as a positive control in different PCR assays. Gene-specific products were confirmed by single PCRs and Sanger sequencing at LGC Genomics GmbH, Berlin, Germany.

2.2. Phenotypic Expression of Virulence Traits. All isolates were tested for their hemolytic (cytolysin) activity and gelatinase and hyaluronidase production in vitro. The expression of the cytolysin activity was tested on agar plates 
TABLE 1: Inoculum concentrations (cfu), virulence genotype, phenotype and results from the chicken embryo lethality assay of 28 Enterococcus isolates from meat turkeys in Germany.

\begin{tabular}{|c|c|c|c|c|c|c|c|c|c|c|c|c|}
\hline \multirow{3}{*}{$\begin{array}{l}\text { ID } \\
2\end{array}$} & \multirow{3}{*}{$\begin{array}{c}\text { Species } \\
\text { E. faecalis }\end{array}$} & \multirow{3}{*}{$\begin{array}{c}\text { Age } \\
\text { Subad }\end{array}$} & \multirow{3}{*}{$\begin{array}{l}\text { Organ } \\
\text { Heart }\end{array}$} & \multirow{3}{*}{$\begin{array}{l}\mathrm{cfu} \\
456\end{array}$} & \multirow{3}{*}{$\begin{array}{l}\text { Detected genes } \\
\text {-operon, cylL } L_{L} L_{S} M B A \\
\text { gelE, asal }\end{array}$} & \multicolumn{2}{|c|}{ Virulence traits by } & \multirow{3}{*}{$\begin{array}{l}\dagger / n \\
8 / 20\end{array}$} & \multirow{2}{*}{\multicolumn{2}{|c|}{ 7-day EMR }} & \multirow{2}{*}{\multicolumn{2}{|c|}{ 7-day ESI }} \\
\hline & & & & & & genotype & phenotype & & & & & \\
\hline & & & & & & CYL, GEL, ASA & GEL & & $40 \%$ & + & 103 & + \\
\hline 5 & E. faecalis & Poult & Yolk sac & 436 & $c y l L_{S}$, gelE, asa 1 & GEL, ASA & GEL & $13 / 20$ & $65 \%$ & ++ & 74 & ++ \\
\hline 30 & E. faecalis & Poult & Yolk sac & 500 & $\begin{array}{c}\text { cyl-operon, } c y l L_{L} L_{S} M B A, \\
\text { gelE, asa1 }\end{array}$ & CYL, GEL, ASA & GEL & $19 / 20$ & $95 \%$ & +++ & 39 & +++ \\
\hline 50 & E. faecalis & Subad & Heart & 852 & gelE, asa 1 & GEL, ASA & GEL & $7 / 20$ & $35 \%$ & + & 111 & + \\
\hline 68 & E. faecalis & Poult & Yolk sac & 856 & gelE & GEL & GEL & $15 / 20$ & $75 \%$ & ++ & 53 & ++ \\
\hline 87 & E. faecalis & Poult & Yolk sac & 428 & $c y l L_{L} L_{S} M A$, gele, asal & GEL, ASA & GEL & $2 / 20$ & $10 \%$ & + & 127 & + \\
\hline 137 & E. faecalis & Poult & Yolk sac & 588 & gelE & GEL & GEL & $6 / 20$ & $30 \%$ & + & 103 & + \\
\hline 159 & E. faecalis & Subad & Heart & 484 & cylA, gelE, asa 1 & GEL, ASA & GEL & $7 / 20$ & $35 \%$ & + & 108 & + \\
\hline 162 & E. faecalis & Subad & Heart & 684 & $\begin{array}{c}\text { cyl-operon, cyl } L_{L} L_{S} M B A, \\
\text { gelE, asa1 }\end{array}$ & CYL, GEL, ASA & GEL & $16 / 20$ & $80 \%$ & ++ & 50 & +++ \\
\hline 165 & E. faecalis & Subad & Heart & 772 & $\begin{array}{c}\text { cyl-operon, cylL } L_{L} L_{S} M B A, \\
\text { gelE, asal }\end{array}$ & CYL, GEL, ASA & GEL & $16 / 20$ & $80 \%$ & ++ & 52 & ++ \\
\hline 6-I & E. faecium & Subad & Air sac & 340 & none & none & none & $2 / 20$ & $10 \%$ & + & 127 & + \\
\hline 44 & E. faecium & Subad & Lung & 304 & none & none & none & $0 / 20$ & $0 \%$ & + & 140 & + \\
\hline 60 & E. faecium & Subad & Air sac & 648 & $c y l L_{L} L_{S} M A$, gele, asa 1 & GEL, ASA & none & $0 / 20$ & $0 \%$ & + & 140 & + \\
\hline 69 & E. faecium & Subad & Lung & 212 & gelE, asa 1 & GEL, ASA & none & $1 / 20$ & $5 \%$ & + & 133 & + \\
\hline 73 & E. faecium & Subad & Air sac & 304 & gelE, asa1 & GEL, ASA & none & $12 / 20$ & $60 \%$ & ++ & 61 & ++ \\
\hline 101 & E. faecium & Poult & Yolk sac & 376 & cylL $L_{S} A$, gele, asa1 & GEL, ASA & none & $10 / 20$ & $50 \%$ & ++ & 76 & ++ \\
\hline 151 & E. faecium & Poult & Yolk sac & 416 & none & none & none & $9 / 20$ & $45 \%$ & ++ & 82 & ++ \\
\hline 153-II & E. faecium & Poult & Yolk sac & 33 & none & none & none & $14 / 20$ & $70 \%$ & ++ & 48 & +++ \\
\hline 157-II & E. faecium & Subad & Lung & 476 & none & none & none & $6 / 20$ & $30 \%$ & + & 103 & + \\
\hline 160 & E. faecium & Subad & Lung & 176 & none & none & none & $7 / 20$ & $35 \%$ & + & 95 & ++ \\
\hline 58 & E. gallinarum & Poult & Yolk sac & 288 & $h y l_{E f m}$ & HYL & $\mathrm{H}, \mathrm{HYL}$ & $0 / 20$ & $0 \%$ & + & 140 & + \\
\hline 77 & E. gallinarum & Poult & Yolk sac & 352 & none & none & H, HYL & $2 / 20$ & $10 \%$ & + & 135 & + \\
\hline 79 & E. gallinarum & Poult & Yolk sac & 304 & gelE & GEL & HYL & $4 / 20$ & $20 \%$ & + & 122 & + \\
\hline 94 & E. gallinarum & Subad & Lung & 288 & none & none & none & $2 / 20$ & $10 \%$ & + & 130 & + \\
\hline 118 & E. gallinarum & Poult & Yolk sac & 280 & $h y l_{E f m}$ & HYL & H, HYL & $6 / 20$ & $30 \%$ & + & 122 & + \\
\hline 127 & E. gallinarum & Poult & Yolk sac & 224 & $h y l_{E f m}$ & HYL & $\mathrm{H}, \mathrm{HYL}$ & $3 / 20$ & $15 \%$ & + & 134 & + \\
\hline 146 & E. gallinarum & Poult & Yolk sac & 404 & $h y l_{E f m}$ & HYL & H, HYL & $2 / 20$ & $10 \%$ & + & 135 & + \\
\hline 156 & E. gallinarum & Poult & Yolk sac & 296 & $h y l_{E f m}$ & HYL & $\mathrm{H}, \mathrm{HYL}$ & $4 / 20$ & $20 \%$ & + & 130 & + \\
\hline
\end{tabular}

EMR, embryo mortality rate; ESI, embryo survival index; Subad, subadult; $\uparrow / n$, dead/tested embryos; CYL, cytolysin; H, beta-hemolysis; GEL, gelatinase; HYL, hyaluronidase; ASA, aggregation substance; virulence classification: +, less, ++, moderately, +++, highly virulent.

with 5\% defibrinated horse blood (Oxoid, Wesel, Germany), incubated at $37^{\circ} \mathrm{C}$ for 24 to 48 hours. Only betahemolysis was assessed as positive reaction. The ability to hydrolyze gelatin was tested on nutrient gelatin plates (nutrient agar from Sifin Diagnostics, Berlin, Germany; nutrient gelatin from Oxoid) incubated at $37^{\circ} \mathrm{C}$ for 24 hours. After incubation, agar plates were stored at $4^{\circ} \mathrm{C}$ for 12 hours. Gelatin hydrolysis was indicated by clear zones around bacterial colonies [35]. Hyaluronidase production was tested on $7 \%$ Columbia sheep blood agar (Oxoid) incubated at $37^{\circ} \mathrm{C}$ for 24 to 48 hours using the Streptococcus equi decapsulation test [36]. Staphylococcus aureus ATCC 25923 was used as a positive control for phenotypic tests.

2.3. Embryo Lethality Assay. Specific pathogen-free (SPF) hatching eggs from VALO BioMedia GmbH (OsterholzScharmbeck, Germany) were used for the experiments. The chicken embryo lethality assay was conducted in 2014 as described by Maasjost [28], following established protocols for the inoculation of the allantoic cavity of ten-day-old chicken embryos [22, 37]. Bacterial growth curve experiments were performed in advance for the three Enterococcus species (strains K923/96, K808/97, and ATCC 49573) to adjust the inoculum by standardized optical density (OD) measurements as described by Maasjost [28]. Compared to Rudolph's [37] experiments, an inoculum between 250 and 500 colony-forming units (cfu) per egg was aimed and verified by viable bacterial cell counts. Twenty embryos were infected per isolate.

Ten embryos served as a negative control in each experiment and were inoculated with $200 \mu$ l sterile PBS instead to evaluate the potential influence of the inoculation. In four infection experiments, uninoculated eggs at the same stage of incubation were placed into the same egg incubator to control for potential independent errors such as egg quality and environmental conditions.

Eggs were incubated at $37.7^{\circ} \mathrm{C}$ and $60-70 \%$ relative humidity and candled daily for seven days post infection (p.i.) to detect dead embryos. The death of embryos was defined as loss of blood vessels and absence of spontaneous movement [38]. Seven days p.i., all surviving embryos were sacrificed at $-20^{\circ} \mathrm{C}$ for two hours. Dead and killed embryos were randomly examined for gross pathology and enterococcal growth. Samples from the yolk sac and, starting on 
day three, from the liver were plated on $7 \%$ Columbia sheep blood agar (Oxoid), incubated at $37^{\circ} \mathrm{C}$ for 24 hours, and evaluated.

Two well-characterized control strains, E. faecalis K923/ 96 (highly virulent) and E. faecium K808/97 (less virulent) as described by Rudolph [37], were kindly provided by Lohmann Tierzucht GmbH (Cuxhaven, Germany) and used as positive controls together with the reference strain E. gallinarum ATCC 49573 (isolated from the chicken intestine).

The embryo mortality rate (EMR) [22] and the embryo survival index (ESI) [37] were determined and used for virulence classifications (Table 2). The EMR was calculated for 20 infected embryos per isolate as the percentage of embryonic death after seven days. The ESI was determined adding the surviving embryos from 20 inoculated eggs from the first to the seventh day p.i. reaching a maximum value of 140 (20 embryos $\times 7$ days). The classification according to the ESI was not always applied for the control strains because absolute numbers of embryos differed partly because of variable viability of the SPF eggs.

2.4. Statistical Analysis. The data analysis was performed in IBM SPSS Statistics version 25 by using descriptive statistics for nominal data. Fisher's exact test for small sample sizes was applied to assess significant differences $(p<0.05)$ in combination with Cramer's $V$ correlation coefficient to estimate the strength of the association $(0=$ no association and $1=$ perfect association). The categorical variables were as follows: Enterococcus species (E. faecalis, E. faecium, or E. gallinarum), presence of virulence traits by genotype (none, one, two, or more traits), age of the turkeys (poults or subadults), EMR (less, moderately, or highly virulent), and ESI (less, moderately, or highly virulent) corresponding to the contents in Table 1.

2.5. Ethical Statement. All experiments were performed in compliance with the animal protection laws of Germany. Experiments utilizing chicken embryos were terminated on day 17 of incubation that means four days prior to hatching [38].

\section{Results}

3.1. Detection of Virulence Genes. Table 1 lists the virulence genes detected in the 28 Enterococcus isolates. The PCR amplicons had the expected size in the gel electrophoreses and were confirmed by Sanger sequencing of short fragments and BLAST analyses (results not shown).

gelE was the most common gene detected in 15 out of 28 isolates, followed by asa $1(12 / 28)$. Between one and up to five different $c y l$ genes were found in nine isolates, while the $c y l$ operon was confirmed only in four E. faecalis isolates and the control strain K923/96 too. Predominant combinations were cyl-operon, $c y l L_{L} L_{S} M B A$, gelE, asa1 $(n=3 ; \mathrm{K} 923 / 96)$ and cylAL $L_{L} L_{S} M$, gelE, asa1 $(n=2)$. The $h y l_{E f m}$ gene was exclusively found in E. gallinarum $(n=5)$. At least one of the virulence genes was found in E. faecalis, while six E. faecium isolates, two E. gallinarum isolates, and the corresponding
TABLE 2: Virulence classification according to the embryo mortality rate (EMR) [22] and embryo survival index (ESI) [37].

\begin{tabular}{lcc}
\hline EMR (\%) & ESI & Virulence \\
\hline$>80$ & $0-50$ & Highly virulent \\
$41-80$ & $51-100$ & Moderately virulent \\
$\leq 40$ & $101-140$ & Less virulent \\
\hline
\end{tabular}

control strains (K808/97 and ATCC 49573) were negative in the PCR analyses (Tables 1 and 3).

3.2. Phenotypic Expression of Virulence Traits. Ten E. faecalis isolates and the control strain K923/96 harbored the gelE gene and showed gelatinase activity. Four E. faecium isolates and one E. gallinarum isolate harbored the gelE gene too, but phenotypic tests were negative. Similarly, none of the $E$. faecalis or E. faecium isolates harboring cyl genes or the whole $c y l$-operon showed hemolytic activity (Table 1). Seven E. gallinarum isolates and the strain ATCC 49573 showed hyaluronidase activity. Five of the isolates and ATCC 49573 harbored the $h y l_{E f m}$ gene; one isolate had only gelE, and one had none of the tested genes. Six E. gallinarum isolates and the strain ATCC 49573 were beta-hemolytic too, while none of the $c y l$ genes or the $c y l$-operon was detected.

3.3. Embryo Lethality Assay. Concentrations of the inocula ranged between 136 and $856 \mathrm{cfu}$ per egg for the $28 \mathrm{En}$ terococcus isolates under study with a mean of $431 \mathrm{cfu}$ (Table 1). Inocula from the three control strains were within this range except for K923/96 that reached $10^{3} \mathrm{cfu}$ in one experiment (Table 3). Dead embryos showed ecchymotic hemorrhages and subcutaneous edema characteristic of sepsis. Bacteriological investigations recovered Enterococcus in pure bacterial cultures from all infected dead and killed embryos tested. No embryo mortality was observed for negative controls during the experiments.

The observed EMR of the isolates (vs. the control strain) at day 7 p.i. ranged from 10 to $95 \%(80-100 \%)$ for E. faecalis (highly virulent K923/96), 0 to $70 \%$ (10-53\%) for E. faecium (less virulent K808/97), and 0 to 30\% (15-60\%) for E. gallinarum (unclassified ATCC 49573). More than half of the isolates $(n=18)$ were found to be less virulent in both classification schemes, including five $E$. faecalis, five $E$. faecium, and all E. gallinarum isolates. Three isolates, two $E$. faecalis, and one E. faecium isolates were classified as highly virulent based on their ESI. Inconsistencies between both classification schemes were observed for two of them (E. faecalis and E. faecium), classified as moderately virulent by their EMR, and for one E. faecium that was classified as moderately virulent by its ESI and less virulent by its EMR (Table 1). The control strains showed discrepancies in their virulence classifications in the six repetitions (Table 3).

3.4. Statistical Analysis. The data from this study were analyzed to identify potential correlations between the Enterococcus species ("species"), the age of infected turkeys ("age"), and the genotypic presence of virulence traits 
TABLE 3: Inoculum concentrations (cfu), virulence genotype, phenotype and results from the chicken embryo lethality assay (performed in six repetitions) of three control strains.

\begin{tabular}{|c|c|c|c|c|c|c|c|c|c|}
\hline ID & Species & cfu & Genotype & Phenotype & $\dagger / n$ & \multicolumn{2}{|c|}{ 7-day EMR } & \multicolumn{2}{|c|}{ 7-day ESI } \\
\hline K923/96 & E. faecalis & 760 & \multirow{6}{*}{ cyl-operon, $c y l L_{L} L_{S} M B A$, gelE, asa1 } & \multirow{6}{*}{ GEL } & $20 / 20$ & $100 \%$ & +++ & 15 & +++ \\
\hline K923/96 & E. faecalis & 660 & & & $19 / 20$ & $95 \%$ & +++ & 35 & +++ \\
\hline K923/96 & E. faecalis & 376 & & & $18 / 20$ & $90 \%$ & +++ & 45 & +++ \\
\hline K923/96 & E. faecalis & 1000 & & & $18 / 20$ & $90 \%$ & +++ & 40 & +++ \\
\hline K923/96 & E. faecalis & 384 & & & $16 / 20$ & $80 \%$ & ++ & 52 & ++ \\
\hline K923/96 & E. faecalis & 548 & & & $8 / 10$ & $80 \%$ & ++ & n.d. & n.d. \\
\hline K808/97 & E. faecium & 352 & \multirow{6}{*}{ None } & \multirow{6}{*}{ None } & $10 / 20$ & $50 \%$ & ++ & 73 & ++ \\
\hline K808/97 & E. faecium & 224 & & & $6 / 20$ & $30 \%$ & + & 104 & + \\
\hline K808/97 & E. faecium & 144 & & & $4 / 20$ & $20 \%$ & + & 120 & + \\
\hline K808/97 & E. faecium & 152 & & & $2 / 20$ & $10 \%$ & + & 130 & + \\
\hline K808/97 & E. faecium & 248 & & & $8 / 15$ & $53 \%$ & ++ & n.d. & n.d. \\
\hline K808/97 & E. faecium & 168 & & & $1 / 10$ & $10 \%$ & + & n.d. & n.d. \\
\hline ATCC 49573 & E. gallinarum & 544 & \multirow{6}{*}{ None } & \multirow{6}{*}{ H, HYL } & $12 / 20$ & $60 \%$ & ++ & 72 & ++ \\
\hline ATCC 49573 & E. gallinarum & 324 & & & $11 / 20$ & $55 \%$ & ++ & 77 & ++ \\
\hline ATCC 49573 & E. gallinarum & 256 & & & $7 / 20$ & $35 \%$ & + & 99 & ++ \\
\hline ATCC 49573 & E. gallinarum & 136 & & & $6 / 20$ & $30 \%$ & + & 117 & + \\
\hline ATCC 49573 & E. gallinarum & 216 & & & $4 / 20$ & $20 \%$ & + & 124 & + \\
\hline ATCC 49573 & E. gallinarum & 232 & & & $3 / 20$ & $15 \%$ & + & 125 & + \\
\hline
\end{tabular}

EMR, embryo mortality rate; ESI, embryo survival index; $\uparrow / n$, dead/tested embryos; H, beta-hemolysis; GEL, gelatinase; HYL, hyaluronidase; virulence classification: +, less, ++, moderately, +++, highly virulent; n.d., not determined because of differing absolute numbers of available viable embryonated SPF eggs.

("genotype") or results from the embryo lethality assay ("EMR" or "ESI"). Statistically significant, strong associations were found between the variables "species" $(p<0.001$ by Fisher's exact test; Cramer's $V=0.68)$ or "age" ( $p=0.011$ by Fisher's exact test; Cramer's $V=0.595)$ and "genotype." Other tested relationships were not significant and revealed moderate or weak associations in Cramer's $V$ statistic. Different analyses are summarized in Table 4; results from the chi-squared test were included for comparison.

\section{Discussion}

Putative virulence traits have frequently been studied in different enterococci of animal and human origin. They are considered to contribute to the pathogenicity of infections [39-41], but the underlying mechanisms often remain unclear. In the present study, 28 Enterococcus isolates from poults and subadult turkeys were investigated for five common virulence traits, namely, the cytolysin toxin, the lytic enzymes gelatinase and hyaluronidase, and the aggregation substance and enterococcal surface proteins. These traits have been selected because they seem to be more prevalent in the clinical course of Enterococcus isolates $[17,18,40]$. The aim was to understand genotype-phenotype correlations and their potential role in pathogenicity using the chicken embryo lethality assay.

The Enterococcus isolates revealed significant speciesdependent differences in the presence of the genotypic traits $(p<0.001$ by Fisher's exact test; Cramer's $V=0.68)$. The $E$. faecalis isolates harbored the majority of virulence genes investigated in this study. Six of ten E. faecium isolates and the corresponding control strain K808/97, however, did not show a virulence genotype or phenotype. Most E. gallinarum harbored the $h y l_{E f m}$ gene only but showed beta-hemolytic and hyaluronidase activity. The latter two Enterococcus species are mainly concomitant bacteria in poultry diagnostics [42] but important nosocomial pathogens of humans and potential food contaminants $[43,44]$.

Phenotypic assays were performed for three out of five virulence traits investigating beta-hemolytic (cytolysin) and enzymatic (gelatinase and hyaluronidase) properties. Genotype-phenotype discrepancies were observed for some isolates and are described for the individual traits below. In general, the lack of phenotypic expression despite genetic evidence indicates the presence of variant ("loss-of-function") or silent genes that can be activated under in vivo conditions [40, 45, 46]. Certain environmental factors such as temperature, ion concentration, or osmolality of the medium can downregulate the genetic expression and negatively affect the gene product [21, 40, 47]. Moreover, structural changes and divergent or newly acquired genes may account for hemolytic or enzymatic properties of isolates that are negative in PCR analyses [40].

The bacteriocin cytolysin has cytotoxic and hemolytic activity [48] and is one of the best-investigated virulence factors in enterococci $[34,49]$. Between one and up to five different $c y l$ genes were found in seven $E$. faecalis and two $E$. faecium isolates from turkeys, which is in good agreement with results from other studies in poultry [50-52]. Four E. faecalis isolates and the control strain K923/96 harbored the cyl-operon but did not show beta-hemolysis. In contrast, the majority of the E. gallinarum isolates and the strain ATCC 49573 were beta-hemolytic, but the corresponding $c y l$ genes could not be confirmed.

The enzyme gelatinase catalyses the hydrolysis of proteins from the extracellular matrix [10]. Gelatinase activity 
TABLE 4: Results from the statistical analyses.

\begin{tabular}{lccr}
\hline Tested variables & Fisher's exact test & Pearson chi-square test & Cramer's $V^{*}$ \\
\hline "Species" × "genotype" & $p<0.001$ & $25.90, \mathrm{~d} f=6, p<0.001$ & 0.680 \\
"Age" × "genotype" & $p=0.011$ & $9.91, \mathrm{~d} f=3, p=0.019$ & 0.595 \\
"Species"× “age" & $p=0.052$ & $5.99, \mathrm{~d} f=2, p=0.050$ & 0.462 \\
"Species" × "EMR/ESI" & $p \geq 0.091$ & $6.78 / 6.89, \mathrm{~d} f=4, p \geq 0.142$ & $0.348 / 0.351$ \\
"Genotype" “"EMR/ESI" & $p \geq 0.202$ & $9.26 / 10.14, \mathrm{~d} f=6, p \geq 0.119$ & $0.407 / 0.426$ \\
"Age" ×"EMR/ESI" & $p \geq 0.686$ & $1.42 / 0.34, \mathrm{~d} f=2, p \geq 0.492$ & $0.225 / 0.109$ \\
\hline
\end{tabular}

${ }^{*} 0=$ no association, $1=$ perfect association; EMR, embryo mortality rate; ESI, embryo survival index.

may favor bacterial colonization and damage host cells $[51,53]$. Although the gelE gene is very common in enterococci, its phenotypic expression can be impaired in vitro but seems to be predominant in clinical isolates from humans and animals [40]. In poultry species, concurrent gelatinase geno- and phenotypes have frequently been detected in E. faecalis from broilers and partridges, and more often than other virulence traits [51,54-56]. These results are consistent with those from isolates of turkey origin under study. All E. faecalis isolates (including K923/96) harbored the gelE gene and showed gelatinase activity, while four $E$. faecium and one E. gallinarum isolates had silent genes only.

The enzyme hyaluronidase is responsible for the breakdown of hyaluronic acids, which facilitates bacterial colonization by decreasing the viscosity of the extracellular matrix [11]. In the present study, the $h y l_{E f m}$ gene was detected neither in E. faecalis nor in E. faecium, but in five of eight E. gallinarum isolates. Interestingly, the strain ATCC 49573 and seven E. gallinarum isolates showed hyaluronidase activity, including those five isolates harboring the $h y l_{F f m}$ gene. One of the two remaining isolates was negative in all PCR assays, and the other harbored the gelE gene only. The knowledge about E. gallinarum and its pathogenic potential is still very limited, and virulence genes have only rarely been investigated so far $[57,58]$.

Aggregation substance and enterococcal surface proteins are likely to facilitate bacterial colonization and persistence in the host by promoting adhesion to surfaces and close bacteria-cell contacts [59]. In poultry, the asa1 gene has been found in E. faecalis and in E. faecium isolates [56, 60,61], whereas the esp gene could not be detected in several studies $[51,52,62,63]$. In the present study, the asal gene was present in eight E. faecalis and in four E. faecium isolates isolated from turkeys, while the esp gene could not be detected. The E. gallinarum isolates did not harbor the adhesin genes.

The 28 Enterococcus isolates (Table 1) and three control strains (Table 3) were investigated using the chicken embryo lethality assay to determine their virulence potential based on the embryo mortality rate (EMR) [22] and the embryo survival index (ESI) [37]. In both classifications, half of the investigated E. faecalis and E. faecium isolates and all eight E. gallinarum isolates were of low virulence $(n=18)$. The mean EMR was $55 \%$ in E. faecalis $(n=10), 31 \%$ in E. faecium $(n=10)$, and $14 \%$ in E. gallinarum $(n=8)$. A moderate association was indicated in Cramer's $V$ statistic between species $(V \leq 0.35)$ or genotype $(V<0.43)$ and the results from the embryo lethality assay, but the differences were not significant (Table 4). These results seem surprising since the isolates were collected from clinically affected birds. Limitations in the availability of embryonated eggs from turkeys only allowed experimental infection of chicken embryos. Because Enterococcus isolates were collected from diseased turkeys, this restriction could affect the actual virulence potential and associated EMRs. Enterococci, however, are opportunistic pathogens that require certain conditions to cause disease and may also benefit from coinfections or underlying diseases $[20,64]$. In a former study, Rudolph [37] tested 27 Enterococcus isolates that originated from joint swabs from brown egg-laying hens suffering from amyloid arthropathy, where E. faecalis is the primary pathogen [1]. Eighteen were identified as highly pathogenic, while the remaining isolates varied in their EMRs from 5 to $90 \%$ and were of low $(n=4)$ or moderate $(n=5)$ virulence. Another study investigated E. cecorum isolates from different sources by inoculation of embryonated SPF eggs from chicken and found animal-specific variations. Pathogenic isolates from poultry species and production systems, where disease outbreaks occur, had higher mean EMRs compared to isolates from birds like turkeys, where disease symptoms only appear sporadically [26].

Several factors (e.g., infection route, embryo quality, and age at inoculation) are known to influence embryo lethality results and impair comparability (summarized in [65]). Previous studies, however, were often not able to draw definite conclusions about whether the infective dose influences the response. These experiments included enterococci $[37,66]$ but also a variety of other bacteria (e.g., $[38,67,68])$. A very recent study by Blanco et al. [65] used $E$. faecalis K923/96 only and with different inoculum concentrations to define the median lethality dose in chicken embryos. The authors found strong positive correlations between the infective dose, the EMR, and the embryo survival time that should be considered for future experiments. The strain K923/96 originated from a chicken with amyloid arthropathy and was highly virulent in seven repetitions in the study by Rudolph [37]. This strain served as the control in the present experiments too, which were conducted in 2014 with equivalent inoculum concentrations. In two out of six repetitions, the strain K923/96 reached the upper classification limit for moderately virulent strains with an EMR of $80 \%$ (Table 3). Likewise, the second control strain K808/97 showed moderate virulence in two out of six repetitions with an increased EMR of about $50 \%$ but was defined as less virulent in Rudolph's experiments [37]. The inocula were with 248 and 352 cfu slightly higher than those in the other four repetitions but reached the intended range 
of 250 to $500 \mathrm{cfu}$ in this study and were similar or less concentrated as those from the study of Rudolph [37]. The ATCC 49573 reference strain also varied in six repetitions between less and moderate in its virulence classifications. An inoculum-based tendency became apparent for this strain too, but not for K923/96 or the 28 isolates under study.

Differences between the two classification results were noticed for three Enterococcus isolates. They were classified more virulent by the ESI than by the EMR by taking the days p.i. into account when embryos died (Table 2). Isolates classified as highly virulent based on their ESI killed more than half (11-14) of 20 inoculated embryos within two days p.i. This initial high mortality is most probably caused by isolate-dependent abilities to grow and invade embryonic tissues, favoring early systemic infections [67]. Ten-day-old chicken embryos do not have a fully developed adaptive immune system to respond to invading pathogens [69].

The isolates from the present study originated from turkey poults with yolk sacculitis $(n=15)$ and from the internal organs of subadult birds $(n=13)$. Commercially raised poults experience different stressors during the first week of life and might be more prone to enterococcal infections compared to subadult birds [70]. Consequently, one would expect that Enterococcus infections in subadult turkeys are caused by virulent strains and by predominant species in poultry disease such as E. faecalis. The Enterococcus isolates from subadult birds belonged mainly to E. faecalis $(n=5)$ and E. faecium $(n=7)$. Significant age-dependent differences were identified in the presence of genotypic traits ( $p=0.011$ by Fisher's exact test), while Cramer's $V$ statistic also showed age-dependent, moderate to strong associations for the Enterococcus species $(V=0.46)$ and the virulence genotype $(V=0.595)$. Eight of 13 isolates from subadult turkeys harbored two or three of the investigated virulence traits, but the identified age differences did not correlate with the results from the embryo lethality assay.

A potential correlation between the isolates' virulence genotype and the pathogenicity for chicken embryos was further investigated independently of the age. Considering the theory of virulence traits conferring pathogenicity, one might expect that a higher virulence potential correlates with the presence of essential genes. Two highly virulent and a moderately virulent E. faecalis isolates indeed harbored the whole $c y l$-operon as well as gelE and asal just as the control strain K923/96, which could enhance their virulence potential. Another E. faecalis isolate, however, had an identical genotype but was less virulent in the embryo lethality assay with comparable inoculum concentrations. This inconsistency became more evident with the highly virulent E. faecium isolate that did not show a corresponding geno- and phenotype (Table 1). Similar conclusions have been reached in virulence comparisons of pathogenic and commensal E. cecorum isolates assuming species-specific mechanisms [26].

\section{Conclusion}

Studies on enterococci often search for genes conferring virulence and antimicrobial resistance to identify potential threats to public health. Comparisons, however, reaching beyond and challenging the concept of virulence traits as intrinsic bacterial properties and determinants of pathogenicity [20] are rare but important for studying opportunistic or secondary pathogens. The three Enterococcus species under study belong to the intestinal microbiota of poultry but were isolated during disease diagnostics from clinically affected birds. As opportunists, their ability to cause disease in turkeys might rather be influenced by the host and its defense mechanisms than by isolate-specific virulence traits. Indeed, half of the E. faecalis, half of the $E$. faecium, and all E. gallinarum isolates under study were of low virulence in the chicken embryo lethality assay. The presence of virulence traits differed markedly between the three Enterococcus species, with E. faecalis harboring the majority of investigated genes. By comparing the results from this study, it became clear that the presence or absence of virulence genes or corresponding phenotypes did not entirely correlate with the isolates' virulence potential and pathogenicity for chicken embryos.

\section{Data Availability}

Three partial 16S rRNA gene sequences (765 bp) from three isolates (IDs 2, 6-I, and 58), representing different Enterococcus species, have been submitted to the NCBI GenBank and are available under accession nos. MN387238MN387240, respectively.

\section{Conflicts of Interest}

The authors declare that there are no conflicts of interest related to this article.

\section{Acknowledgments}

The authors want to thank Elke Dyrks, Gabriele Grotehenn, and Birgit Göllner for their technical assistance.

\section{Supplementary Materials}

Table S1: details on multiplex PCR primers used for virulence gene detection. Table S2: details on primers used for individual PCRs and Sanger sequencing. (Supplementary Materials)

\section{References}

[1] A. E. Blanco, M. Barz, W. Icken et al., "Twenty years of amyloid arthropathy research in chickens," World's Poultry Science Journal, vol. 72, no. 3, pp. 495-508, 2016.

[2] J. D. Tankson, J. P. Thaxton, and Y. Vizzier-Thaxton, "Pulmonary hypertension syndrome in broilers caused by Enterococcus faecalis," Infection and Immunity, vol. 69, no. 10, pp. 6318-6322, 2001.

[3] R. H. Olsen, C. Frantzen, H. Christensen, and M. Bisgaard, "An investigation on first-week mortality in layers," Avian Diseases, vol. 56, no. 1, pp. 51-57, 2012.

[4] W. E. C. Moore and W. B. Gross, "Liver granulomas of turkeys: causative agents and mechanism of infection," Avian Diseases, vol. 12, no. 3, pp. 417-422, 1968. 
[5] B. Dolka, D. Chrobak-Chmiel, M. Czopowicz, and P. Szeleszczuk, "Characterization of pathogenic Enterococcus cecorum from different poultry groups: broiler, chickens, layers, turkeys, and waterfowl," PLoS One, vol. 12, no. 9, Article ID e0185199, 18 pages, 2017.

[6] R. C. Moellering Jr., "The enterococcus: a classic example of the impact of antimicrobial resistance on therapeutic options," Journal of Antimicrobial Chemotherapy, vol. 28, no. 1, pp. 1-12, 1991.

[7] C. P. Hunt, "The emergence of enterococci as a cause of nosocomial infection," British Journal of Biomedical Science, vol. 55, no. 2, pp. 149-156, 1998.

[8] M. S. C. Gilmore, The Enterococci-Pathogenesis, Molecular Biology and Antibiotic Resistance, ASM Press, Washington, DC, USA, 2002.

[9] N. Shankar, P. Coburn, C. Pillar, W. Haas, and M. Gilmore, "Enterococcal cytolysin: activities and association with other virulence traits in a pathogenicity island," International Journal of Medical Microbiology, vol. 293, no. 7-8, pp. 609618, 2004.

[10] P. L. Makinen, D. B. Clewell, F. An, and K. K. Makinen, "Purification and substrate specificity of a strongly hydrophobic extracellular metalloendopeptidase ("gelatinase") from Streptococcus faecalis (strain 0G1-10)," The Journal of Biological Chemistry, vol. 264, pp. 3325-3334, 1989.

[11] W. Hynes and S. L. Walton, "Hyaluronidases of gram-positive bacteria," FEMS Microbiology Letters, vol. 183, no. 2, pp. 201-207, 2000.

[12] L. B. Rice, L. Carias, S. Rudin et al., "A potential virulence Gene, $h y l_{E f m}$, predominates in Enterococcus faeciumof clinical origin," The Journal of Infectious Diseases, vol. 187, no. 3, pp. 508-512, 2003.

[13] D. Galli, F. Lottspeich, and R. Wirth, "Sequence analysis of Enterococcus faecalis aggregation substance encoded by the sex pheromone plasmid pAD1," Molecular Microbiology, vol. 4, no. 6, pp. 895-904, 1990.

[14] B. Kreft, R. Marre, U. Schramm, and R. Wirth, “Aggregation substance of Enterococcus faecalis mediates adhesion to cultured renal tubular cells," Infection and Immunity, vol. 60, no. 1, pp. 25-30, 1992.

[15] S. B. Olmsted, G. M. Dunny, S. L. Erlandsen, and C. L. Wells, "A plasmid-encoded surface protein on Enterococcus faecalis augments its internalization by cultured intestinal epithelial cells," The Journal of Infectious Diseases, vol. 170, no. 6, pp. 1549-1556, 1994.

[16] A. Toledo-Arana, J. Valle, C. Solano et al., "The enterococcal surface protein, Esp, is involved in Enterococcus faecalis biofilm formation," Applied and Environmental Microbiology, vol. 67, no. 10, pp. 4538-4545, 2001.

[17] J. W. Chow, L. A. Thal, M. B. Perri et al., "Plasmid-associated hemolysin and aggregation substance production contribute to virulence in experimental enterococcal endocarditis," Antimicrobial Agents and Chemotherapy, vol. 37, no. 11, pp. 2474-2477, 1993.

[18] K. V. Singh, X. Qin, G. M. Weinstock, and B. E. Murray, "Generation and testing of mutants of Enterococcus faecalis in a mouse peritonitis model," The Journal of Infectious Diseases, vol. 178, no. 5, pp. 1416-1420, 1998.

[19] E. N. Vergis, N. Shankar, J. W. Chow et al., "Association between the presence of enterococcal virulence factors gelatinase, hemolysin, and enterococcal surface protein and mortality among patients with bacteremia due to Enterococcus faecalis," Clinical Infectious Diseases, vol. 35, no. 5, pp. 570-575, 2002.
[20] A. Casadevall and L. Pirofski, "Host-pathogen interactions: the attributes of virulence," The Journal of Infectious Diseases, vol. 184, pp. 337-344, 2001.

[21] F. Cafini, F. Gómez-Aguado, M. T. Corcuera et al., "Genotypic and phenotypic diversity in Enterococcus faecalis: is agar invasion a phathogenicity score?," Revista Española de Quimioterapia, vol. 28, no. 2, pp. 101-108, 2015.

[22] R. E. Wooley, P. S. Gibbs, T. P. Brown, and J. J. Maurer, "Chicken embryo lethality assay for determining the virulence of avian Escherichia coli isolates," Avian Diseases, vol. 44, no. 2, pp. 318-324, 2000.

[23] P. S. Gibbs, J. J. Maurer, L. K. Nolan, and R. E. Wooley, "Prediction of chicken embryo lethality with the avian Escherichia coli traits complement resistance, colicin V production, and presence of the increased serum survival gene cluster (iss)," Avian Diseases, vol. 47, no. 2, pp. 370-379, 2003.

[24] K. Sturzenhecker, "Untersuchungen zur Virulenz von Campylobacter jejuni und Campylobacter coli am standardisierten Infektionsmodell 'bebrütetes Hühnerei'," Doctoral thesis, Dr. Med. Vet., Freie Universität Berlin, Berlin, Germany, 1995.

[25] L. B. Borst, M. M. Suyemoto, S. Keelara, S. E. Dunningan, J. S. Guy, and H. J. Barnes, "A chicken embryo lethality assay for Pathogenic Enterococcus cecorum," Avian Diseases, vol. 58, no. 2, pp. 244-248, 2014.

[26] A. Jung, M. Metzner, and M. Ryll, "Comparison of pathogenic and non-pathogenic Enterococcus cecorum strains from different animal species," BMC Microbiology, vol. 17, no. 1, p. 13, 2017.

[27] J. Maasjost, K. Mühldorfer, S. C. de Jäckel, and H. M. Hafez, "Antimicrobial susceptibility patterns of Enterococcus faecalis and Enterococcus faecium isolated from poultry flocks in Germany," Avian Diseases, vol. 59, no. 1, pp. 143-148, 2015.

[28] J. Maasjost, "Antimicrobial resistance and virulence of enterococci isolated from poultry," Doctoral thesis, Dr. Med. Vet., Freie Universität Berlin, Berlin, Germany, 2017, https:// refubium.fu-berlin.de/handle/fub188/13090.

[29] C. R. Jackson, P. J. Fedorka-Cray, and J. B. Barrett, "Use of a genus- and species-specific multiplex PCR for identification of enterococci," Journal of Clinical Microbiology, vol. 42, no. 8, pp. 3558-3565, 2004.

[30] B. M. Deasy, M. C. Rea, G. F. Fitzgerald, T. M. Cogan, and T. P. Beresford, "A rapid PCR based method to distinguish between Lactococcus and Enterococcus," Systematic and Applied Microbiology, vol. 23, no. 4, pp. 510-522, 2000.

[31] K. Mühldorfer, S. Schwarz, J. Fickel, G. Wibbelt, and S. Speck, "Genetic diversity of Pasteurella species isolated from European vespertilionid bats," Veterinary Microbiology, vol. 149, no. 1-2, pp. 163-171, 2011.

[32] V. Vankerckhoven, T. Van Autgaerden, C. Vael et al., "Development of a multiplex PCR for the detection of asa1, gelE, $c y l A$, esp, and $h y l$ genes in enterococci and survey for virulence determinants among European hospital isolates of Enterococcus faecium," Journal of Clinical Microbiology, vol. 42, no. 10, pp. 4473-4479, 2004.

[33] I. L. B. C. Camargo, M. S. Gilmore, and A. L. C. Darini, "Multilocus sequence typing and analysis of putative virulence factors in vancomycin-resistant and vancomycin-sensitive Enterococcus faecium isolates from Brazil," Clinical Microbiology and Infection, vol. 12, no. 11, pp. 1123-1130, 2006.

[34] F. B. Gaspar, M. T. B. Crespo, and M. F. S. Lopes, "Proposal for a reliable enterococcal cytolysin production assay avoiding apparent incongruence between phenotype and genotype," Journal of Medical Microbiology, vol. 58, no. 8, pp. 1122-1124, 2009. 
[35] T. E. E. dela Cruz and J. M. O. Torres, Gelatin Hydrolysis Test Protocol, ASM Microbe Library, 2012.

[36] R. G. E. Murray and R. H. Pearce, "The detection and assay of hyaluronidase by means of mucoid streptococci," Canadian Journal of Research, vol. 27, no. 5, pp. 254-264, 1949.

[37] B. Rudolph, "Investigations to Enterococcus faecalis as possible factor for etiology of amyloid arthropathy of brown layers," Doctoral thesis, Dr. Med. Vet., Freie Universität Berlin, Berlin, Germany, 2004, https://refubium.fu-berlin.de/ handle/fub188/9099.

[38] K. Polakowska, M. W. Lis, W. M. Helbin et al., "The virulence of Staphylococcus aureus correlates with strain genotype in a chicken embryo model but not a nematode model," Microbes and Infection, vol. 14, no. 14, pp. 1352-1362, 2012.

[39] B. D. Jett, M. M. Huycke, and M. S. Gilmore, "Virulence of enterococci," Clinical Microbiology Reviews, vol. 7, no. 4, pp. 462-478, 1994.

[40] T. Semedo, M. A. Santos, M. F. Lopes et al., "Virulence factors in food, clinical and reference enterococci: a common trait in the genus?," Systematic and Applied Microbiology, vol. 26, no. 1, pp. 13-22, 2003.

[41] K. Fisher and C. Phillips, "The ecology, epidemiology and virulence of Enterococcus," Microbiology, vol. 155, no. 6, pp. 1749-1757, 2009.

[42] D. Stępień-Pyśniak, A. Marek, T. Banach et al., "Prevalence and antibiotic resistance of Enterococcus strains isolated from poultry," Acta Veterinaria Hungarica, vol. 64, no. 2, pp. 148-163, 2016.

[43] G. Giraffa, "Enterococci from foods," FEMS Microbiology Reviews, vol. 26, no. 2, pp. 163-171, 2002.

[44] H. Hanchi, W. Mottawea, K. Sebei, and R. Hammami, "The genus Enterococcus: between probiotic potential and safety concerns-an update," Frontiers in Microbiology, vol. 9, Article ID 1791, 16 pages, 2018.

[45] T. J. Eaton and M. J. Gasson, "Molecular screening of Enterococcus virulence determinants and potential for genetic exchange between food and medical isolates," Applied and Environmental Microbiology, vol. 67, no. 4, pp. 1628-1635, 2001.

[46] R. Creti, M. Imperi, L. Bertuccini et al., "Survey for virulence determinants among Enterococcus faecalis isolated from different sources," Journal of Medical Microbiology, vol. 53, no. 1, pp. 13-20, 2004.

[47] R. Gross, "Signal transduction and virulence regulation in human and animal pathogens," FEMS Microbiology Letters, vol. 104, no. 3-4, pp. 301-326, 1993.

[48] R. A. Segarra, M. C. Booth, D. A. Morales, M. M. Huycke, and M. S. Gilmore, "Molecular characterization of the Enterococcus faecalis cytolysin activator," Infection and Immunity, vol. 59, no. 4, pp. 1239-1246, 1991.

[49] C. Cox, P. Coburn, and M. Gilmore, "Enterococcal cytolysin: a novel two component peptide system that serves as a bacterial defense against eukaryotic and prokaryotic cells," Current Protein \& Peptide Science, vol. 6, no. 1, pp. 77-84, 2005.

[50] J. Champagne, M. S. Diarra, H. Rempel et al., "Development of a DNA microarray for enterococcal species, virulence, and antibiotic resistance gene determinations among isolates from poultry," Applied and Environmental Microbiology, vol. 77, no. 8, pp. 2625-2633, 2011.

[51] M. S. Diarra, H. Rempel, J. Champagne, L. Masson, J. Pritchard, and E. Topp, "Distribution of antimicrobial resistance and virulence genes in Enterococcus spp. and characterization of isolates from broiler chickens," Applied and
Environmental Microbiology, vol. 76, no. 24, pp. 8033-8043, 2010.

[52] S. A. Khan, M. S. Nawaz, A. A. Khan, S. L. Hopper, R. A. Jones, and C. E. Cerniglia, "Molecular characterization of multidrugresistant Enterococcus spp. from poultry and dairy farms: detection of virulence and vancomycin resistance gene markers by PCR," Molecular and Cellular Probes, vol. 19, no. 1, pp. 27-34, 2005.

[53] L. R. Thurlow, V. C. Thomas, S. Narayanan, S. Olson, S. D. Fleming, and L. E. Hancock, "Gelatinase contributes to the pathogenesis of endocarditis caused by Enterococcus faecalis," Infection and Immunity, vol. 78, no. 11, pp. 4936-4943, 2010.

[54] P. Poeta, D. Costa, N. Klibi, J. Rodrigues, and C. Torres, "Phenotypic and genotypic study of gelatinase and betahaemolysis activities in faecal enterococci of poultry in Portugal," Journal of Veterinary Medicine Series B, vol. 53, no. 5, pp. 203-208, 2006.

[55] I. Y. Hwang, S. K. Lim, H. O. Ku et al., "Occurrence of virulence determinants in fecal Enterococcus faecalis isolated from pigs and chickens in Korea," Journal of Microbiology and Biotechnology, vol. 21, no. 12, pp. 1352-1355, 2011.

[56] N. Silva, G. Igrejas, J. Vaz et al., "Virulence factors in enterococci from partridges (Alectoris rufa) representing a food safety problem," Foodborne Pathogens and Disease, vol. 8, no. 7, pp. 831-833, 2011.

[57] A. Gonçalves, P. Poeta, N. Silva et al., "Characterization of vancomycin-resistant enterococci isolated from fecal samples of ostriches by molecular methods," Foodborne Pathogens and Disease, vol. 7, no. 9, pp. 1133-1136, 2010.

[58] I. C. Olapido, A. I. Sanni, and S. Swarnakar, "Virulence potential of Enterococcus gallinarum strains isolated from selected Nigerian traditional fermented foods," Journal of BioScience and Biotechnology, vol. 3, pp. 97-104, 2014.

[59] I. G. Sava, E. Heikens, and J. Huebner, "Pathogenesis and immunity in enterococcal infections," Clinical Microbiology and Infection, vol. 16, no. 6, pp. 533-540, 2010.

[60] P. Poeta, D. Costa, J. Rodrigues, and C. Torres, "Detection of genes encoding virulence factors and bacteriocins in fecal enterococci of poultry in Portugal," Avian Diseases, vol. 50, no. 1, pp. 64-68, 2006.

[61] A. Kasimoğlu-Doğru, Y. E. Gençay, and N. D. Ayaz, "Comparison of virulence gene profiles of Emterococcus faecium and Enterococcus faecalis chicken neck skin and faecea isolates," Kafkas Universitesi Veteriner Fakultesi Dergisi, vol. 16, pp. S129-S133, 2010.

[62] A. M. Hammerun and L. B. Jensen, "Prevalence of esp, encoding the enterococcal surface protein, in Enterococcus faecalis and Enterococcus faecium isolates from hospital patients, poultry, and pigs in Denmark," Journal of Clinical Microbiology, vol. 40, no. 11, p. 4396, 2002.

[63] V. Seputienne, A. Bogdaite, M. Ruzauskas, and E. Suziedeliene, "Antibiotic resistance genes and virulence factors in Enterococcus faecium and Enterococcus faecalis from diseased farm animals: pigs, cattle and poultry," Polish Journal of Veterinary Science, vol. 15, no. 3, pp. 431-438, 2012.

[64] S. P. Brown, D. M. Cornforth, and N. Mideo, "Evolution of virulence in opportunistic pathogens: generalism, plasticity, and control," Trends in Microbiology, vol. 20, no. 7, pp. 336-342, 2012.

[65] A. E. Blanco, M. Barz, W. Icken et al., "Chicken embryo lethality assay for determining the lethal dose and virulence of Enterococcus faecalis," Avian Pathology, vol. 46, no. 5, pp. 548-555, 2017. 
[66] T. A. Abdul-Aziz and S. N. el-Sukhon, "Pathogenicity of Enterococcus hirae for chicken embryos and betamethasonetreated chicks," Research in Veterinary Science, vol. 56, no. 3, pp. 397-398, 1994.

[67] N. H. Nabbut and I. H. Khatib, "Virulence of Escherichia coli strains for chicken embryos," Avian Diseases, vol. 22, no. 1, pp. 10-15, 1978.

[68] H.-S. Seo, S.-Y. Cha, M. Kang, and H.-K. Jang, "Chicken embryo lethality assay for determining the virulence of Riemerella anatipestiferisolates," Avian Pathology, vol. 42, no. 4, pp. 387-392, 2013.

[69] M. T. Hincke, M. Da Silva, N. Guyot et al., "Dynamics of structural barriers and innate immune components during incubation of the avian egg: critical interplay between autonomous embryonic development and maternal anticipation," Journal of Innate Immunity, vol. 11, no. 2, pp. 111-124, 2019.

[70] Y. Wein, Z. Geva, E. Bar-Shira, and A. Friedman, "Transportrelated stress and its resolution in Turkey pullets: activation of a pro-inflammatory response in peripheral blood leukocytes," Poultry Science, vol. 96, no. 8, pp. 2601-2613, 2017. 


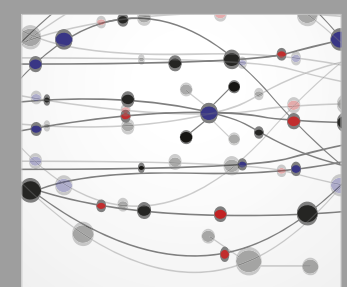

The Scientific World Journal
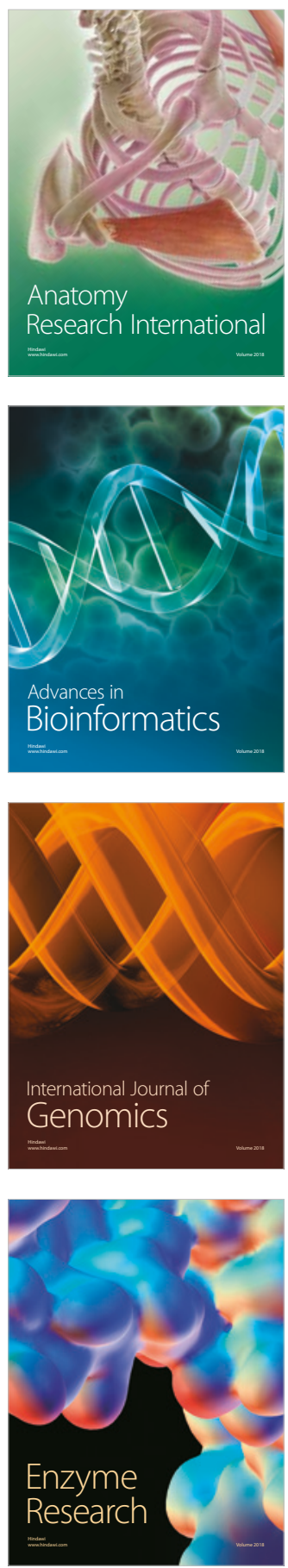
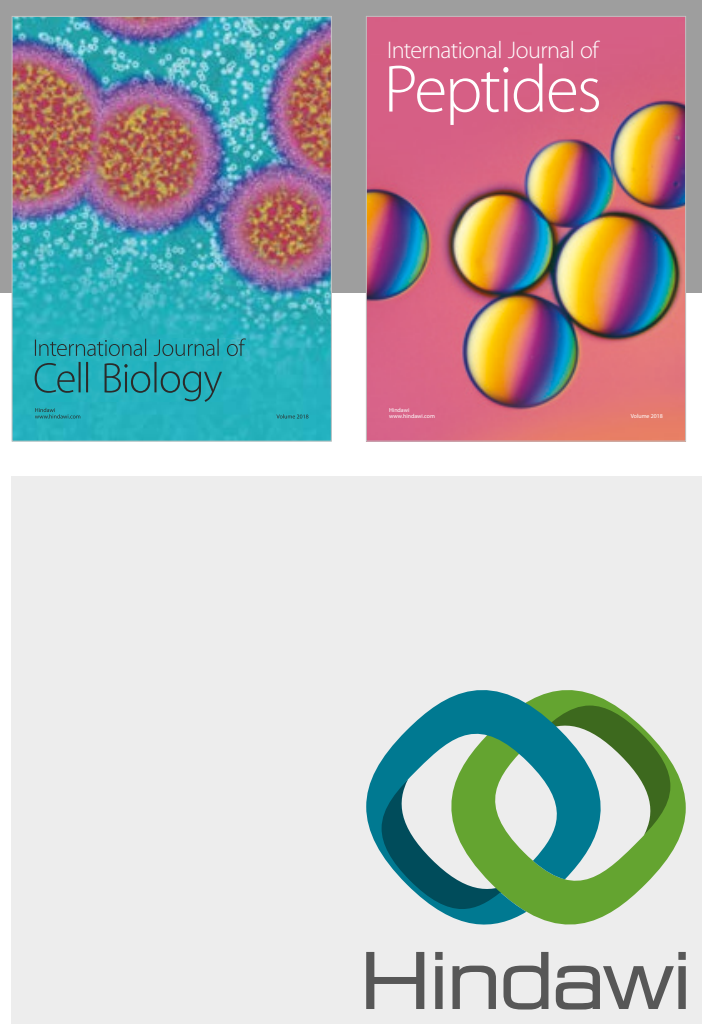

Submit your manuscripts at

www.hindawi.com
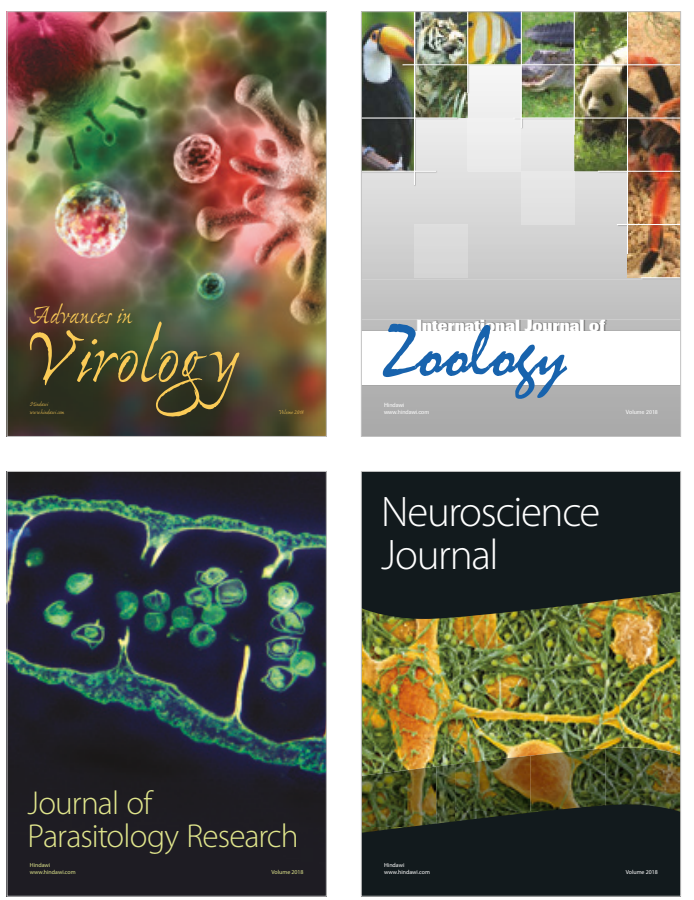
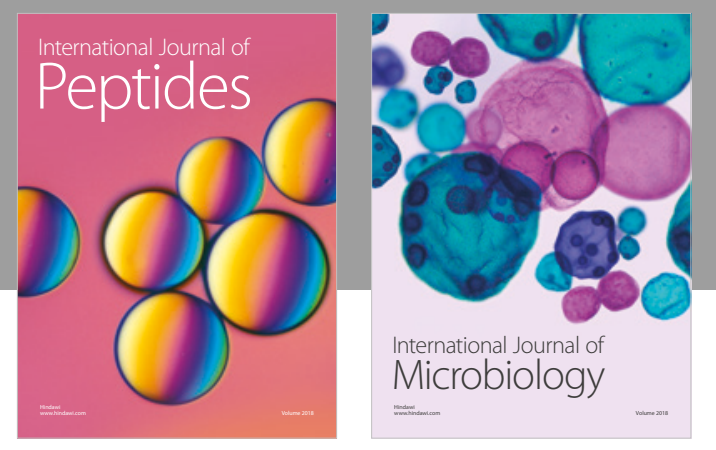

nternational Journal of Microbiology
Journal of
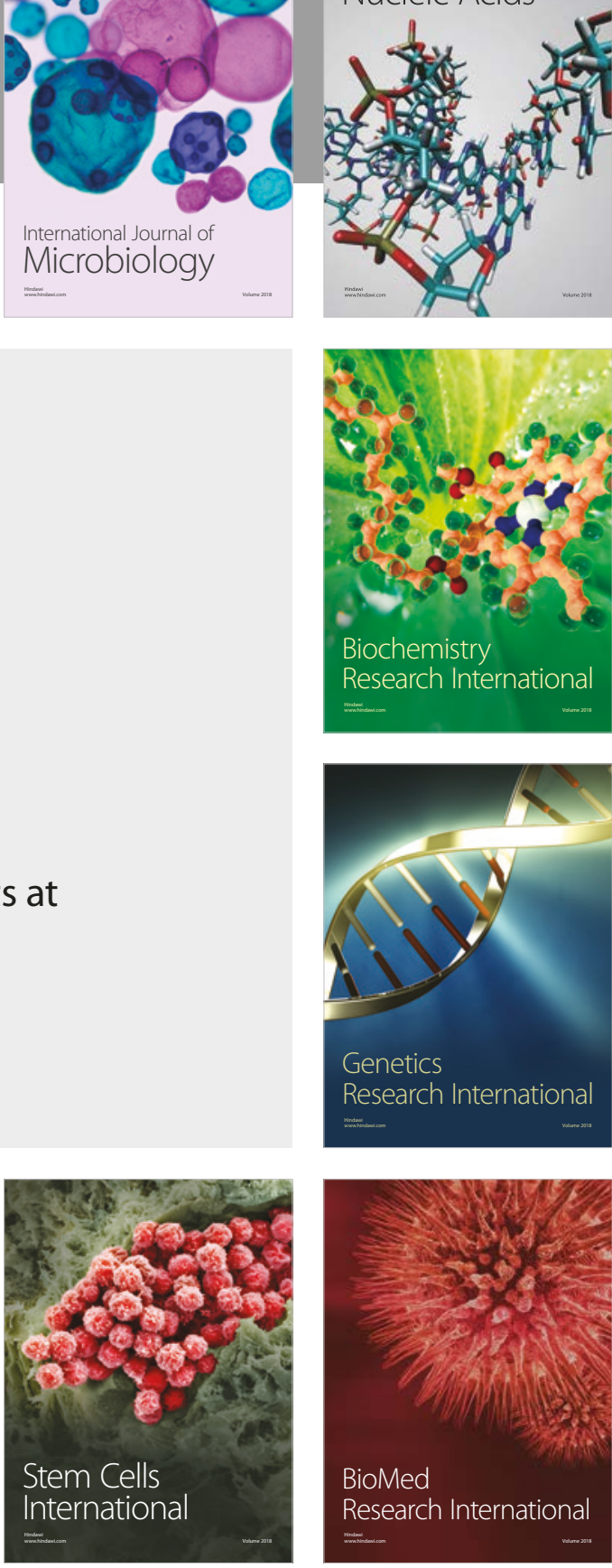
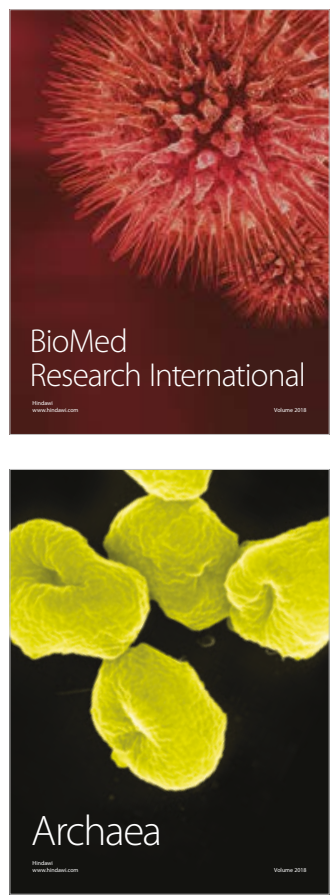